\title{
Desigualdades en salud y opinión pública. Un análisis de las preferencias redistributivas en la provincia de Córdoba, Argentina*
}

\section{Inequalities in Health and the Public Opinion. An Analysis of the Redistributive Preferences in the Córdoba Province, Argentina}

\section{Desigualdades em saúde e opinião pública. Uma análise das preferencias redistributivas na província de Córdoba, Argentina}

\author{
Fecha de recepción: 25 de enero de 2018. Fecha de aprobación: 23 de mayo de \\ 2018. Fecha de publicación: 27 de mayo de 2019 \\ DOI: https://doi.org/10.11144/Javeriana.rgps18-36.dsop \\ Marcelo Nazarenoa \\ Universidad Nacional de Córdoba, Argentina \\ ORCID: 0000-0002-5757-5986 \\ María Marta Santillán Pizarro \\ CIECS (CONICET y UNC) y Universidad Católica de Córdoba, Argentina \\ ORCID: 0000-0001-5191-9234
}

\footnotetext{
Cómo citar este artículo: Nazareno M, Santillán Pizarro MM. Desigualdades en salud y opinión pública. Un análisis de las preferencias redistributivas en la provincia de Córdoba, Argentina. Revista Gerencia y. Políticas de Salud. 2019;18(36). https://doi.org/10.11144/Javeriana.rgps18-36.dsop

Artículo de investigación

Una versión preliminar fue presentada en el XIII Congreso Nacional de Ciencia Política organizado por la Sociedad Argentina de Análisis Político (SAAP), realizado en la ciudad de Buenos Aires, Argentina, en agosto de 2017.

Autor de correspondencia. Correo electrónico: nazarenomarcelo55@gmail.com
} 


\section{Resumen}

América Latina muestra elevadas desigualdades en salud. Su reducción solo es posible a través de políticas públicas redistributivas, cuya viabilidad depende de una opinión pública que reconozca estas desigualdades y que apoye las acciones redistributivas del Estado. A pesar de la relevancia, son escasos los trabajos en América Latina sobre percepciones de desigualdad y preferencias redistributivas en salud. A partir del análisis de una encuesta poblacional en la provincia de Córdoba, Argentina, hacemos un aporte en este sentido. Nuestros principales hallazgos muestran: (i) más del $50 \%$ de la población percibe alta o muy alta desigualdad en salud; (ii) más del $90 \%$ tiene preferencias redistributivas; (iii) para casi la mitad estas preferencias son muy intensas; (iv) las posibilidades de tener preferencias muy intensas dependen inversamente del ingreso y directamente de ser mujer, del temer que la desigualdad genere problemas al entorno familiar y de la pertenencia a organizaciones voluntarias.

Palabras clave: salud, desigualdad, percepciones, preferencias redistributivas, políticas, Argentina

\section{Abstract}

Latin America has deep inequalities in health issues. Reducing this gap will be possible only by implementing redistributive public policies. Whether they are suitable or not depends on the fact that the public becomes aware of these inequalities and supports the redistributive actions carried out by the State. Studies on the inequality perceptions and redistributive preference in health issues in Latin America are quite scant despite their relevance. Based on the analysis of a population survey applied to the Cordoba Province, Argentina, we are providing herein a contribution on this topic. Our main findings indicate that: (i) more than $50 \%$ of the population perceives either a high o very high inequality in health services; (ii) more than $90 \%$ say to prefer redistributive measures; (iii) almost a half of their preferences are quite intense; (iv) the probability that people have very intense preferences depends inversely on their income and directly on the fact of being a woman, fearing that inequality would result in problems for the family environment, and being part of a volunteer organization.

Keywords: health, inequality, perceptions, redistributive preferences, policies, Argentina

\section{Resumo}

América Latina mostra elevadas desigualdades em saúde. Sua redução só é possível por meio de políticas públicas redistributivas, cuja viabilidade depende de una opinião pública que reconheça tais desigualdades e apoje as ações redistributivas do Estado. Embora a relevância, são escassos os trabalhos na América Latina sobre percepções de desigualdade e preferencias redistributivas em saúde. A partir da análise de um inquérito populacional na província de Córdoba, Argentina, fazemos uma contribuição neste sentido. Nossos principais achados mostram: (i) mais de $50 \%$ da população percebe alta ou muito alta desigualdade em saúde; (ii) mais de $90 \%$ tem preferencias redistributivas; (iii) para quase a metade essas preferencias são muito intensas; (iv) as possibilidades de ter preferencias muito intensas dependem inversamente das rendas e diretamente de ser mulher, do medo da desigualdade gerar problemas ao entorno familiar e de pertencer a organizações voluntárias.

Palavras chave: saúde, desigualdade, percepções, preferencias redistributivas, políticas, Argentina 


\section{Introducción}

Las desigualdades entre diferentes grupos sociales en cuanto a la salud - que incluyen el estado de salud, las condiciones de vida saludables y el acceso a la atención médica adecuada - han ganado centralidad en las últimas décadas, principalmente en referencia a los países en desarrollo. Tanto en trabajos académicos como en la agenda de organismos internacionales (principal, pero no exclusivamente, la Organización Mundial de la Salud) se reconoce que estas desigualdades se encuentran entre los más importantes obstáculos que enfrenta hoy el objetivo de mejorar sustancialmente la salud poblacional, superada la fase de importantes avances que se dieron en muchos países en desarrollo durante las décadas de los setenta, ochenta y noventa del siglo pasado.

Nos parece importante remarcar el énfasis que desde la Comisión de los Determinantes Sociales de la Salud (DSS) se hace en la necesidad de reducir la desigualdad en salud. El modelo entiende que el estado de salud de las personas es el resultado de múltiples factores (hay varios modelos sobre determinantes estructurales, intermedios y próximos) y que las desigualdades evitables (a las que la Comisión denomina "inequidades") son injustas. Las políticas para reducir estas desigualdades son complejas y no se circunscriben solo al sistema de salud, sino que van desde mejoras en el entorno que incluyen el barrio, la vivienda, el acceso a servicios, la educación y el trabajo, hasta la protección social e incluso la redistribución de recursos de poder (1).

Diferentes informes señalan, respecto a América Latina, que los progresos alcanzados a nivel nacional ocultan diferenciales entre distintos grupos poblacionales (definidos por localización geográfica, género, raza y/o ingresos). Es decir, que dichos progresos se dieron manteniendo, e incluso aumentando, las brechas entre habitantes del campo y la ciudad, entre regiones periféricas y centrales, entre mujeres y varones, entre pueblos originarios y descendientes de inmigrantes europeos y entre sectores de bajos ingresos y aquellos de ingresos más altos. En este contexto, el desafío latinoamericano del siglo XXI consiste en reducir la aún elevada desigualdad que se verifica no solo en salud sino también en múltiples dimensiones como ingreso, trabajo, vivienda y educación, entre tantas otras, que hacen de la región la más desigual del mundo. 
Como en todas las dimensiones de desigualdad, la reducción de las desigualdades en salud solo es posible a través de la implementación de políticas públicas diseñadas con este objetivo. Estas políticas deben apuntar a elevar el nivel sanitario de la población más desfavorecida, sin hacer recaer sobre ella el costo de su implementación. Esto es, deben ser políticas sanitarias redistributivas. Y más allá de las características específicas del diseño de estas políticas, una cuestión clave es su viabilidad política, la cual depende, en buena medida y entre otros factores relevantes, del apoyo que tengan en la opinión pública, tal como reconoce la literatura sobre políticas públicas. Esto es, la implementación efectiva y duradera de políticas de salud redistributivas estará condicionada por la existencia, en una parte relevante de la población, de preferencias redistributivas y, como veremos, de cuáles son los factores determinantes de tales preferencias.

A pesar de la relevancia de la opinión pública respecto a esquemas redistributivos en salud, la producción de trabajos sobre países de América Latina que se ocupen de las actitudes de los ciudadanos en relación con políticas redistributivas es limitada. En este contexto, nuestro trabajo es una contribución para el llenado de este vacío. Sus objetivos son establecer las características y alcance de las preferencias redistributivas en salud en una de las provincias más importantes de la Argentina, como así también establecer cuáles son los factores que explican las variaciones de estas preferencias a nivel individual.

Estos objetivos son compatibles con un enfoque multidimensional como el de los DSS, ya que de lo que se trata es de establecer en qué medida en la opinión pública hay registros de los niveles de desigualdad en salud, como así también la adhesión pública a posibles políticas de reducción de estas desigualdades, más allá de que tales políticas involucren al propio sistema de salud o a otros ámbitos y factores que inciden sobre aquellas desigualdades.

El marco de los determinantes sociales de la salud (DSS) reconoce que la mayor parte de la carga mundial de morbilidad y las causas principales de las inequidades en salud (que se encuentran en todos los países y que podrían evitarse) configura el resultado de las condiciones en las que las personas nacen, viven, trabajan y envejecen, y de los sistemas que se utilizan para combatir la enfermedad $(2,3)$. De manera que el interés por medir desigualdades en salud refiere básicamente a la identificación de diferencias en la salud de las personas de distintos grupos poblacionales, como consecuencia de la 
forma en la que las personas viven y acceden a los servicios de salud, que a su vez son consecuencia de desigualdades sociales (4). Distintos autores se han basado en los DSS y demostrado la relación entre situación socioeconómica, inequidad de ingresos y desigualdades en salud en el contexto latinoamericano (5). Así, por ejemplo, Almeida menciona distintos estudios que demuestran desigualdades tanto en los servicios de salud como en el estado de salud a favor de los ricos, independientemente del indicador que se utilice en la medición (6).

En la agenda internacional, distintas conferencias — desde Alma Ata, la Conferencia Internacional sobre la Población y el Desarrollo (CIPD) de El Cairo (1994), el Plan de Acción Regional de esta conferencia (1996), la Cumbre del Milenio (2000), entre otras- han planteado las prioridades en materia de salud y han destacado las desigualdades entre los países y, más importante, dentro de ellos. Hacen un llamado a los países a reducirlas, principalmente en lo que refiere a salud en la niñez, salud materna, reducción del hambre, salud sexual y reproductiva en general y en la adolescencia en particular; combatir el VIH/Sida y otras enfermedades de transmisión sexual, entre otras. Reconocen desigualdades entre distintas áreas geográficas y entre los diferentes sectores socioeconómicos, culturales o étnicos.

Como seguimiento al cumplimiento de los objetivos y metas planteados en estas conferencias, se han realizado diferentes evaluaciones sobre los países de América Latina que demuestran que la mayoría de los países han avanzado en la concreción de las metas vinculadas a la salud de la población en general, aunque no todos lograron alcanzarlas. A pesar de estos avances a niveles agregados, las evaluaciones destacan que el reto pendiente refiere a la reducción de las desigualdades en salud entre diferentes sectores. Cuando las fuentes de datos permitieron medirlas, ellas revelan que en general persisten las desigualdades entre zonas geográficas, entre zonas urbanas y rurales, entre distintos niveles educativos de las madres, siendo los pueblos indígenas las poblaciones más rezagadas (7).

En este marco conceptual y empírico adquiere relevancia establecer en qué medida estas desigualdades "objetivas" son percibidas por la población y hasta dónde esa percepción implica un apoyo hacia políticas redistributivas que tiendan a reducirlas. Sobre la base de una encuesta poblacional representativa realizada en la provincia de Córdoba, Argentina, analizamos la percepción de la población respecto a las desigualdades en atención sa- 
nitaria, la percepción respecto a las obligaciones y acciones que el Estado realiza o debe realizar en este sentido, y los factores que inciden en las preferencias redistributivas de los ciudadanos, todas cuestiones que tienen relevancia en relación con el apoyo político activo a eventuales políticas redistributivas que puedan reducir o atenuar las desigualdades presentes.

La Argentina es un país cuyo estudio puede implicar aportes importantes sobre el modo que se constituye la opinión pública respecto a las desigualdades en salud y la aplicación de esquemas redistributivos. Es un país muy urbanizado, con uno de los ingresos per cápita más altos de la región y con una amplia cobertura en salud a través de un sistema de salud muy extendido y complejo. En efecto, el sistema de salud en Argentina está compuesto por tres subsistemas poco articulados entre sí y de gran heterogeneidad en el interior de cada uno: (1) el sistema público, que depende de la administración pública (nacional, provincial y municipal), con diferentes grados de complejidad en cada provincia y municipio, ofrece cobertura gratuita a través de la red de hospitales y centros de salud públicos; (2) el de la seguridad social obligatoria, integrado por las obras sociales, se financia con los aportes de los trabajadores formales y presta atención a ellos y a sus familias; (3) el subsistema privado, compuesto por una red de profesionales y centros de salud independientes que prestan sus servicios a pacientes que pagan por los servicios directamente o lo hacen a través de una obra social o un sistema de salud prepago (8).

Es, además, uno de los países de la región, junto con Uruguay y Cuba, que redujo la mortalidad en todas las edades muy tempranamente, todo un logro en materia de salud. Específicamente en lo que refiere a la mortalidad infantil —es decir, a la relación entre la cantidad de niños que mueren en el primer año de vida por cada mil que nacen en el mismo año-, Argentina es uno de los países de menor nivel en América Latina (9). El país ha reducido las tasas de mortalidad infantil en las últimas décadas, pasando de valores de 25,6 en 1990 y alcanzando un nivel de 9,7 muertes por cada 1000 nacimientos en el año 2015 (10).

A pesar de estos resultados a niveles agregados, el análisis de las desigualdades de la mortalidad infantil muestra una realidad menos favorable: según el método que se utilice para analizar las brechas entre provincias -única desagregación posible debido a la disponibilidad de información de calidad-, puede concluirse que las desigualdades no se estarían reduciendo 
o, más grave aún, se estarían incrementando (11). Además, el país presenta desigualdades relativamente elevadas en cuanto al estado de salud de diferentes grupos sociodemográficos. De este modo, parece mostrar como pocos países latinoamericanos los límites, en cuanto a reducción de la desigualdad, de los esquemas sanitarios desarrollados en décadas anteriores. Es en estas situaciones de "umbral" en las que la opinión pública es decisiva y de gran relevancia en torno a la posibilidad de cambios de paradigmas.

Por otra parte, la Argentina es un país federal en el que las jurisdicciones provinciales tienen amplias competencias gubernamentales y administrativas; entre otras, el control casi total de la salud pública, en la cual la presencia del Estado nacional es marginal. De este modo, es en los gobiernos provinciales en los cuales recae la responsabilidad mayor en relación con la (potencial) implementación de esquemas sanitarios redistributivos (8).

La provincia de Córdoba, por su parte, presenta características económicas y sociodemográficas particularmente interesantes para una exploración de la opinión pública relativa a desigualdad y políticas redistributivas. Es la segunda provincia del país en cuanto a población y desarrollo económico, al tiempo que presenta una multiplicidad de realidades sociales y productivas.

Con base en información de la Dirección de Estadísticas e Información de Salud de la Nación, los resultados permiten afirmar que la provincia presenta una situación más favorable que la del país en su conjunto: menores niveles de mortalidad infantil, menores niveles de desigualdad entre regiones y menor proporción de muertes evitables. Sin embargo, los datos ponen en evidencia un aumento de las desigualdades en el tiempo, con independencia del método de medición utilizado (12).

El trabajo se organiza de la siguiente manera. En la siguiente sección abordamos las perspectivas teóricas que dan cuenta de los factores determinantes de preferencias redistributivas. Después de presentar en la segunda sección la fuente de datos y los métodos utilizados, en la siguiente sección nos ocupamos del análisis de la encuesta poblacional en relación con percepciones de desigualdad, preferencias redistributivas y determinantes de tales preferencias. Finalizamos con algunas reflexiones a modo de conclusión, haciendo especial referencia a las implicancias que los resultados de nuestro análisis tienen sobre los tipos de políticas y las estrategias políticas que pueden maximizar los niveles de viabilidad política de esquemas redistributivos. 


\section{Las teorías sobre los determinantes de las preferencias redistributivas en salud}

Uno de los principales modos para avanzar hacia una reducción sustantiva de las desigualdades en salud es la implementación de políticas sanitarias y de reforma de los sistemas globales de salud que reduzcan sustancialmente las diferencias en el acceso a la prevención, a la atención adecuada y a condiciones socioambientales saludables $(13,14)$.

Más allá de su contenido sustantivo, las políticas orientadas a una reducción sustancial de las desigualdades en salud deben cumplir dos condiciones:

1. Tener un contenido redistributivo

2. Ser políticamente viables

Respecto a la primera condición, si bien parece obvia ya que toda reducción de desigualdades implica procesos redistributivos, en servicios básicos como la atención sanitaria en los cuales las desigualdades emergen de un balance entre el financiamiento del servicio y la distribución del acceso a este, es posible que la reducción de las desigualdades en uno de estos aspectos se realice a costa del incremento de estas en el otro, enmascarando, de este modo, el mantenimiento de las desigualdades "netas" o aun haciéndolas más profundas. En otras palabras, que la reducción de la desigualdad del "lado de la oferta" más que se compense por el aumento de la desigualdad por el "lado de la demanda", o viceversa. Como remarca Wagstaff (14), al señalar la ineficacia de las políticas de salud en los países en desarrollo para reducir las desigualdades: "Esto indica que las políticas destinadas a combatir las desigualdades en el sector de la salud deberían dirigirse a reducir las desigualdades tanto del lado de la oferta (por ejemplo, la calidad y la disponibilidad de servicios de salud), como en el lado de la demanda (ingresos, conocimientos y, especialmente conocimientos relacionados específicamente con la salud, accesibilidad de los servicios de salud, disponibilidad de agua potable segura, saneamiento, etc.)".

Respecto a la segunda condición, esta incide críticamente sobre la primera, en cuanto toda política redistributiva implica un cambio del statu quo y enfrenta, por ende, desafíos políticos planteados por las clases o grupos perjudicados por este cambio. 
En este sentido, un elemento clave (si bien no el único relevante) de la viabilidad política de una política redistributiva es el estado de la opinión pública o de las preferencias de los ciudadanos (favorable o desfavorable) respecto a la implementación de políticas de este tipo.

En el área de la salud, si bien las desigualdades han merecido una creciente atención en la literatura y en la agenda de las políticas públicas y de los organismos internacionales, tanto respecto a los países desarrollados como en desarrollo $(14,15)$, los estudios sobre las actitudes y las preferencias respecto a políticas redistributivas en esta dimensión son escasísimos en América Latina en general y la Argentina en particular.

La literatura más numerosa y sofisticada sobre los factores que inciden en las preferencias redistributivas ha sido escrita por economistas y se ocupa mayoritariamente de la desigualdad en la dimensión “ingresos" (16-19). Los trabajos que se ocupan específicamente de las preferencias redistributivas en el área de la salud son muchísimo menos numerosos y, en buena medida, toman los elementos analíticos desarrollados por los economistas en la dimensión ingresos y los adaptan a las particularidades de la dimensión sanitaria.

La reducción de desigualdades en salud implica, entre otros numerosos aspectos, hacer más accesible la atención sanitaria adecuada a aquellos que por diferentes motivos (ingresos, raza, género, localización geográfica, etc.), o están excluidos de ella, o acceden con dificultad y cuando lo hacen reciben una atención de menor calidad. Esto implica, por un lado, reorientar los esfuerzos de inversión en salud para mejorar el acceso y la atención recibida por estos sectores y, por el otro, financiar estos esfuerzos sin "penalizar" a los sectores de menores ingresos, esto es, extrayendo recursos de los sectores de ingresos más altos. Se trata, entonces, de aplicar esquemas redistributivos que incrementen ( in costo adicional para ellos) las posibilidades de acceso al sistema de salud de quienes están total o parcialmente excluidos de ella.

Una pregunta de gran relevancia es quiénes son los individuos que con más probabilidades apoyarán y/o demandarán políticas redistributivas de este tipo, contribuyendo a su implementación y viabilidad política. Desde un punto de vista teórico, existen varias respuestas alternativas a esta pregunta. En uno de los escasos trabajos que se ocupan de esta cuestión en los países desarrollados, James y Savedoff (20) presentan sistemáticamente una variedad de perspectivas sobre los factores que explican la mayor o 
menor voluntad de los individuos de sostener esquemas redistributivos en salud. En lo que sigue nos basaremos en este trabajo, si bien introduciendo algunos cambios y ampliaciones, para presentar un panorama sumario de las alternativas teóricas respecto a los determinantes de las preferencias redistributivas en salud.

Los autores distinguen un primer grupo de tres perspectivas que tienen en común, en línea con los enfoques económicos y de la elección racional, la asunción de actores individuales racionales y autointeresados para quienes el bienestar de los demás no incide en su propio bienestar y que, por lo tanto, apoyarán políticas redistributivas o no según sea el balance de los costos y beneficios individuales implicados. En otros términos, un individuo apoyará políticas redistributivas si estas implican un beneficio neto para sí mismo, con independencia de sus implicancias para los demás.

El primero de estos enfoques asume, además, que los individuos establecen este cálculo focalizándose en el presente. Una implicación directa de esta asunción es que el apoyo a esquemas redistributivos en atención sanitaria provendrá de quienes tienen menores ingresos (quienes normalmente tienen además dificultades para acceder a atención y cuidados sanitarios de calidad y que no pagarán costos por el cambio del sistema) y están enfermos, por un lado, y de quienes estando enfermos tienen problemas de acceso por otros motivos. Por su parte, quienes tienen ingresos altos (estén enfermos o no) se opondrán a las políticas redistributivas.

El segundo enfoque complejiza el análisis al incorporar la incertidumbre sobre el futuro en el cálculo de beneficios derivados de la redistribución. En este caso, la relación entre estado de salud y el apoyo a políticas redistributivas deja de ser tan directo como en el caso anterior, ya que quien está sano sabe que tiene probabilidades de que en el futuro esté enfermo. En este caso, entonces, puede suponerse que quienes estén enfermos y quienes estén sanos pero están en condiciones de prever que requerirán acceso al sistema de salud, y en ambos casos tienen problemas (por su bajo nivel de ingreso o por otras razones) para acceder adecuadamente al sistema, apoyarán esquemas redistributivos. En el caso de quienes tengan altos ingresos, la previsión de este enfoque es similar a la del anterior: se opondrán a las políticas redistributivas.

Finalmente, dentro de este primer grupo de teorías se encuentra la perspectiva que a la asunción de racionalidad autointeresada y a la incertidumbre 
respecto al futuro, agrega la aversión al riesgo de los individuos. De este punto de vista se deriva que, aun personas de altos ingresos y/o con pocas perspectivas de necesitar acceder al sistema de salud, apoyarán políticas redistributivas (pagando su costo) si su aversión al riesgo es suficientemente alta. La inversa (que quienes tienen bajos ingresos no apoyarán políticas redistributivas si tienen baja aversión al riesgo) no es cierta: quienes tienen problemas para acceder al sistema de salud apoyarán políticas redistributivas aunque su aversión al riesgo sea baja, ya que no tienen nada que "apostar" contra un futuro potencialmente negativo en cuanto no correrán con los costos de la redistribución.

Siendo tan relevante como parece ser, la variable "aversión al riesgo" tiene el grave problema de que solo puede medirse a través de instrumentos específicos (preguntas especialmente diseñadas) ya que al ser una predisposición independiente de condiciones objetivas es inadecuado hacerlo a través de proxys basadas en tales condiciones (a menos que estuviera probada una fuerte asociación ente tales condiciones y la mayor o menor aversión al riesgo).

Un segundo grupo de perspectivas teóricas (también desarrollado mayormente por economistas) asume que la mentalidad de los individuos es más compleja que la asumida por las teorías del racionalismo autointeresado y abre cierto espacio para actitudes y conductas altruistas, sin que esto implique necesariamente la anulación completa de un cálculo racional autointeresado.

También en este grupo existen diferentes enfoques. Uno de ellos, formulado por Becker y adoptado bajo el nombre de "beneficio del donante" por el análisis costo-beneficio de las políticas públicas (21), postula la interdependencia entre las utilidades de los individuos, de modo tal que el bienestar de uno de ellos es afectado por el bienestar de los otros, en el sentido que una mala (buena) condición de los demás reduce (aumenta) el bienestar del individuo de referencia. Siendo esto así, los individuos tendrán disposición a contribuir al bienestar de los demás, pero no lo harán irrestrictamente, sino solo en la medida que el beneficio derivado de dar supere el costo que implica la donación (20).

Otra entrada analítica dentro este enfoque es la propuesta originalmente por Margolis (22) quien postula una diferencia en la preferencia de los individuos según lo que esté implicado sean bienes privados, por un lado y merit goods, 
por el otro. Según qué tipo de bienes se trate, estarán implicadas diferentes lógicas. En el caso de los bienes privados, los individuos se comportarán de acuerdo con una racionalidad autointeresada. Pero en el caso de los merit goods, como miembros de una comunidad los individuos derivan bienestar de la cantidad de este tipo de bienes que están disponibles socialmente y a los que, por definición, deberían tener acceso todos los miembros de la comunidad. De este modo, los individuos estarán dispuestos a financiar "en su justa medida" (de acuerdo con sus posibilidades) la provisión de este tipo de bienes colectivos. De este modo, Margolis demuestra formalmente que a medida que los recursos individuales de los que dispone un individuo aumentan, aumentará más que proporcionalmente su disposición a financiar los merit goods. Dado que los servicios de atención a la salud son generalmente considerados merit goods, el modelo de Margolis puede ser usado para el análisis de preferencias redistributivas en la dimensión sanitaria.

Más allá de las diferencias en los supuestos y desarrollo analítico que existen entre estos dos enfoques, ambos coinciden en establecer, como consecuencia lógica de sus modelos, que la predisposición a apoyar esquemas redistributivos dependerá del ingreso, pero de un modo inverso al postulado por la perspectiva racional-autointeresada focalizada en el presente: cuanto mayor sea el ingreso, independientemente de su estado de salud, mayor será el apoyo a políticas redistributivas, en tanto mayor se hace el beneficio marginal derivado de la contribución (al bienestar de los demás o a la provisión de bienes colectivos) vis a vis el costo marginal de dicha contribución.

Un tercer enfoque que nos parece adecuado incluir dentro de la perspectiva del racionalismo altruista y que no es considerado por James y Savedoff (20), se vincula con la idea, desarrollada sobre todo en el ámbito de los estudios sobre las conductas electorales, de que las decisiones políticas a nivel individual (por ejemplo, el voto) se toman mirando no solo la realidad individual, sino también el contexto social, en la medida en que según las condiciones de dicho contexto, se derivarán (futuros) beneficios o perjuicios individuales. Según esta mirada, los individuos toman decisiones políticas adoptando una perspectiva "sociotrópica" para establecer los beneficios esperados de tales decisiones. La salud es un ámbito especialmente propicio para que opere una racionalidad de este tipo, dadas las elevadas probabilidades que una parte importante de la población perciba las consecuencias individuales que tienen las condiciones generales de su contexto social. En materia de preferencias redistributivas, cabe esperar según este modelo que, 
con independencia de sus condiciones de salud y de ingresos, un individuo apoyará políticas de redistribución en la medida que perciba potenciales consecuencias negativas de la desigualdad para sí mismo y su grupo familiar.

Además de estos dos grupos de teorías desarrolladas mayormente por economistas, James y Savedoff (20) presentan otros dos grupos de teorías vinculadas a la biología evolucionista y a la sociología-antropológica respectivamente.

En cuanto al primer grupo, el argumento específicamente biológico-evolucionista se extiende para explicar el altruismo entre individuos (humanos) que no son genéticamente cercanos, a partir del concepto de "altruismo recíproco": un individuo estará dispuesto a ayudar a otros integrantes del grupo con el que se dan sus interacciones más intensas —y por ende a apoyar una redistribución - en cuanto asume que, a su vez, los miembros de este grupo lo ayudarán si lo necesita en el futuro.

Por su parte, las teorías sociológico-antropológicas postulan que la predisposición a contribuir al bienestar de los demás es función de la intensidad de las interacciones sociales. Entre individuos que interactúan intensamente se desarrollan vínculos psicológicos y emocionales que los predisponen a contribuir al bienestar del grupo, con independencia de los beneficios personales que esta contribución pueda implicar en el futuro.

Como señalan James y Savedoff (20), las previsiones empíricas de estos dos grupos de teorías respecto a las actitudes redistributivas son casi indistinguibles: en ambos casos cabe esperar que quienes interactúen más intensamente con grupos vulnerables en cuanto a su estado de salud, tengan una mayor predisposición a apoyar esquemas redistributivos, independientemente de sus condiciones de ingresos. De este modo, trabajadores del área de salud y madres (en países como buena parte de los latinoamericanos, en los que las mujeres llevan la mayor carga de la contribución familiar al bienestar) son los grupos en los que cabe esperar un mayor apoyo a políticas redistributivas en la atención sanitaria.

En la tabla 1 se ofrece un resumen de las perspectivas teóricas y de sus previsiones respecto a las características de quienes tienen actitudes favorables a la implementación de esquemas redistributivos y las variables que en cada caso se consideran relevantes para explicar las preferencias redistributivas. 
Tabla 1. Teorías sobre preferencias distributivas en salud

\begin{tabular}{lll}
\multicolumn{1}{c}{ Teorías } & \multicolumn{1}{c}{$\begin{array}{c}\text { Grupos c/ preferencias redistri- } \\
\text { butivas }\end{array}$} & \multicolumn{1}{c}{ Variable y signo esperado } \\
\hline $\begin{array}{lll}\text { Autointerés en el } \\
\text { presente }\end{array}$ & Enfermos con bajos ingresos & $\begin{array}{l}\text { - Salud } \\
\text { - Ingresos }\end{array}$ \\
\hline Incertidumbre & Bajos ingresos (sanos y enfermos & - Ingresos \\
\hline Aversión al riesgo & $\begin{array}{l}\text { Bajo ingresos; altos ingresos } \\
\text { adversos al riesgo }\end{array}$ & + Aversión al riesgo \\
\hline Beneficio del donante & Altos ingresos & + Ingresos \\
\hline Merit Goods & Altos ingresos & + ingresos \\
\hline Sociotropismo & Perceptores de riesgo social & $\begin{array}{l}\text { + Percepción de perjuicios de la } \\
\text { desigualdad }\end{array}$ \\
\hline Altruismo recíproco & Redes de interacción & + Pertenencia a grupos voluntarios \\
\hline Solidaridad Emocional & Redes de interacción & + Pertenencia a grupos voluntarios \\
\end{tabular}

Fuente: elaboración propia

\section{Datos y métodos}

Los datos sobre percepción de las desigualdades y preferencias redistributivas provienen de una encuesta diseñada a tal fin y aplicada al universo constituido por la población que reside en la provincia de Córdoba. Se implementó en julio-agosto de 2016 en el marco del Programa de Estudio e Incidencia sobre las Desigualdades Sociales (Presides), del Instituto Federal de Gobierno, Facultad de Ciencias Políticas y Relaciones Internacionales de la Universidad Católica de Córdoba. Se realizó sobre una muestra probabilística de 800 casos, representativa de las personas de 18 años y más, de las ciudades de la provincia de Córdoba de 10.000 y más habitantes.

Para analizar los factores que inciden en las preferencias redistributivas se aplicaron modelos econométricos logit binominal, tomando como variable dependiente preferencias redistributivas activas (valor de la variable $=1 \mathrm{si}$ el individuo pertenece a la categoría de quienes están muy de acuerdo con que el Estado lleva adelante acciones para reducir la desigualdad y creen que el Estado no hace nada al respecto o lo que hace es insuficiente; valor de la variable $=0$ en caso contrario). Las variables independientes de los modelos se establecieron en función de las perspectivas teóricas presentadas anteriormente. Los detalles de la definición de las variables y su medición se desarrollan en el anexo. 


\section{Resultados}

Respecto a las percepciones de desigualdad en salud, en la encuesta se preguntó ¿cómo considera que son las desigualdades en las posibilidades de recibir atención médica?. En la figura 1 se presentan los resultados. Puede verse que entre quienes piensan que las desigualdades en atención médica son "muy altas" y "altas" suman más del $53 \%$ de la población, mientras que quienes piensan que las desigualdades son "bajas", "muy bajas" o que "no hay desigualdades" apenas superan el $13 \%$.

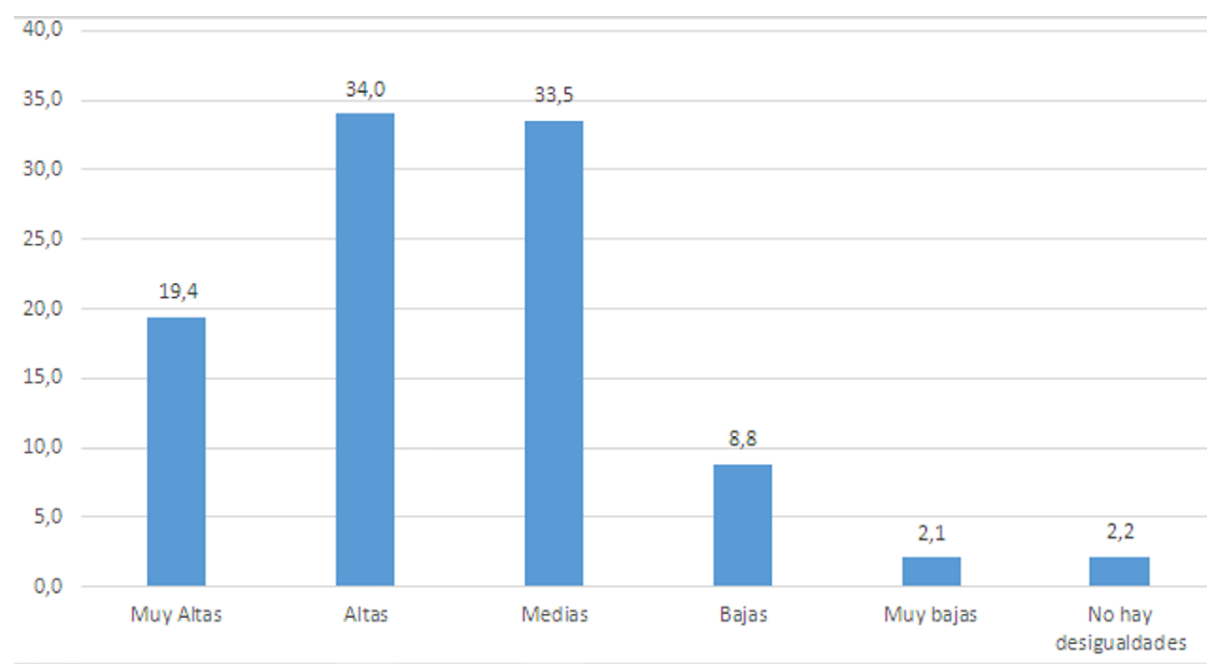

Figura 1. Percepción de desigualdad en posibilidades de recibir atención médica adecuada en la provincia de Córdoba. En porcentajes. $n=800$

Fuente: elaboración propia con base en encuesta Presides 2016

Por cierto, estas percepciones no necesariamente implican actitudes favorables a la intervención del Estado para corregirlas o morigerarlas. Una primera aproximación respecto a actitudes de este tipo son las opiniones relativas a la injusticia de determinadas desigualdades. En la figura 2 puede verse la distribución de porcentajes de la población según la respuesta a la pregunta: las posibilidades de recibir atención médica adecuada pueden ser desiguales entre diferentes personas de una sociedad iLe parece que esta situación es muy justa, algo justa, ni justa ni injusta, algo injusta o muy injusta? El porcentaje de quienes piensan que esta situación es muy injusta es de casi el $54 \%$, y sumados a los de quienes creen que esta situación es algo injusta alcanzan casi el $87 \%$. 


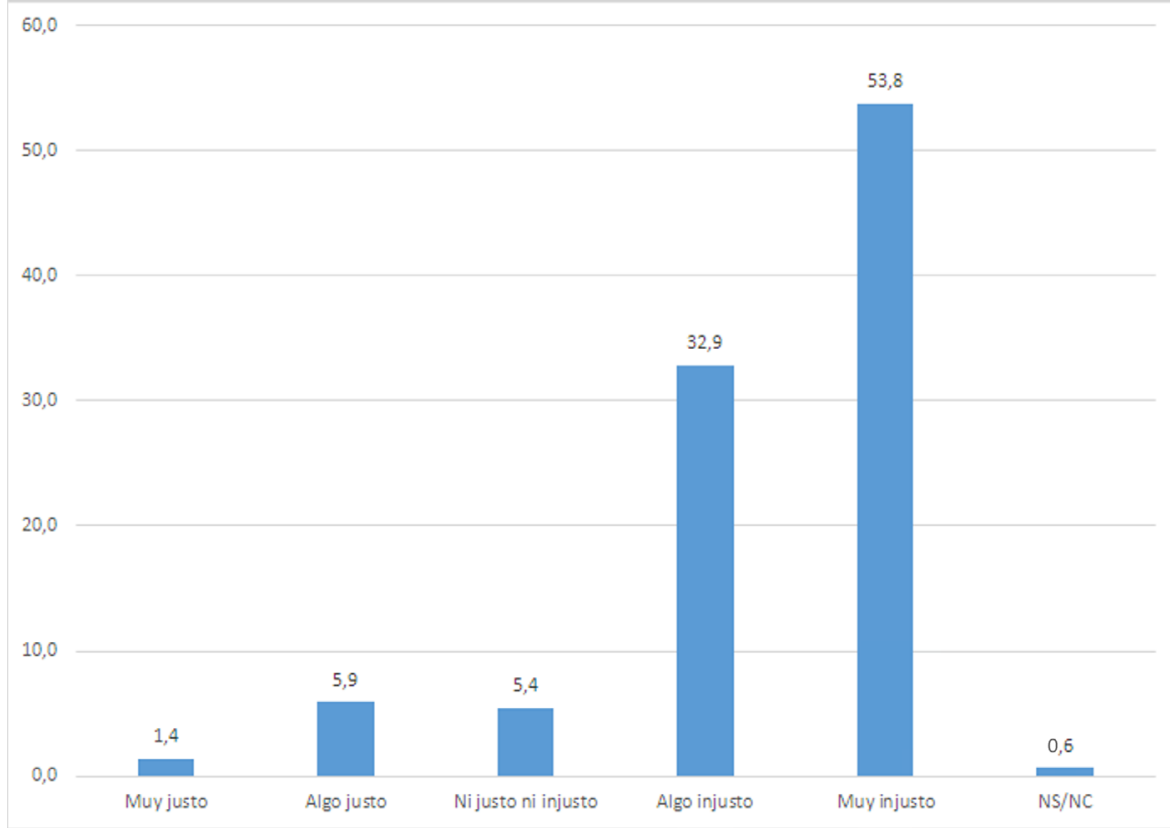

Figura 2. Percepción de justicia-injusticia respecto a situaciones de desigualdad en posibilidades de recibir atención médica adecuada en la provincia de Córdoba. En porcentajes. $n=800$

Fuente: elaboración propia con base en encuesta Presides 2016

Estos elevados porcentajes relativos a la injusticia de la desigualdad en la atención médica permiten pensar que una gran proporción de la población tendrá una actitud favorable a la intervención del Estado para la corrección de tales desigualdades. Esta presunción se confirma cuando se examinan las repuestas a la pregunta iel Estado debe realizar acciones para reducir la desigualdad en salud? La figura 3 muestra los porcentajes correspondientes a las diferentes respuestas. Una abrumadora mayoría de la población (más del 95\%) está muy de acuerdo o de acuerdo con que el Estado debe intervenir en este sentido. 


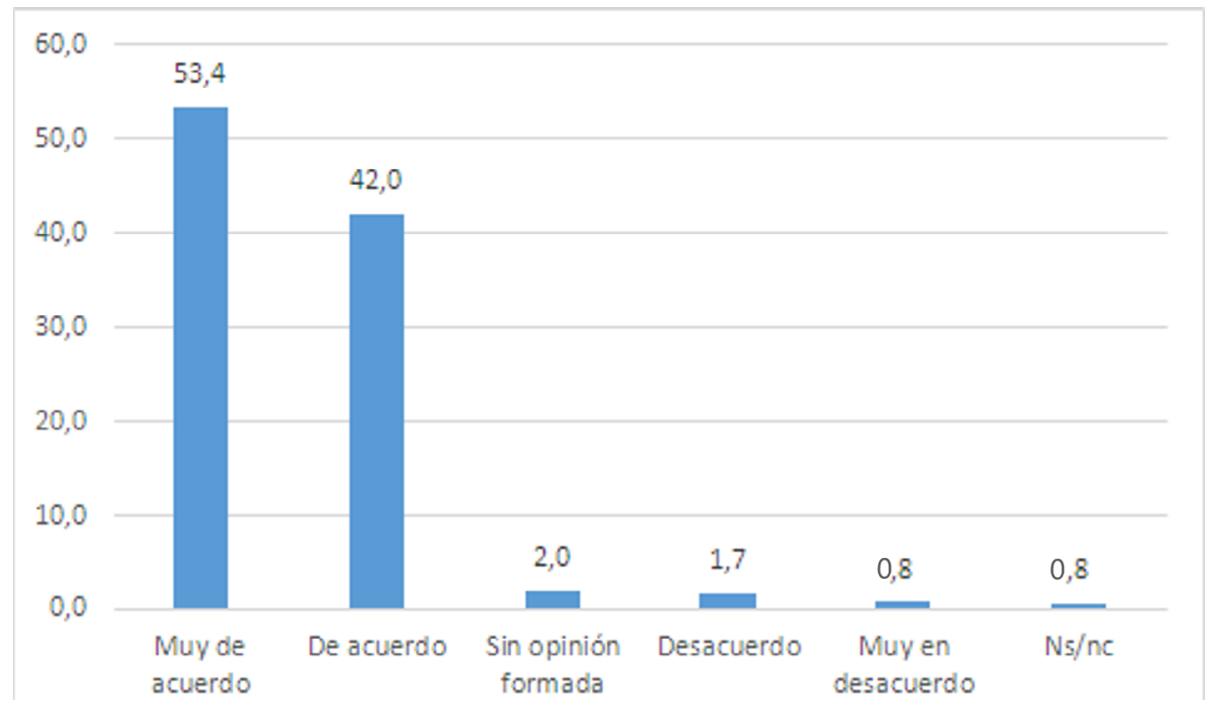

Figura 3. Percepción de la población respecto a la necesidad de que el Estado realice acciones para reducir la desigualdad en salud. Provincia de Córdoba. En porcentajes. $n=800$

Fuente: elaboración propia con base en encuesta Presides 2016

Estas actitudes respecto a la acción del Estado no necesariamente indican posiciones redistributivas. En efecto, puede darse el caso de que quien cree que el Estado debe intervenir para reducir las desigualdades considere que el Estado ya interviene en este sentido y que dicha intervención es suficiente en términos de reducción de desigualdades, con lo cual no se considerarán necesarias intervenciones redistributivas adicionales.

De aquí que, con el fin de establecer más adecuadamente quiénes tienen preferencias redistributivas se hicieron dos preguntas adicionales respecto a la intervención del Estado para reducir las desigualdades en salud. En la primera de ellas se preguntó a los encuestados: cel Estado está realizando acciones para reducir la desigualdad en salud? En la segunda se les preguntó: ¿Considera que estas acciones son insuficientes, suficientes o excesivas para reducir la desigualdad en salud?!

Las figuras 4 y 5 muestran la distribución de la población según las respuestas a estas preguntas. Puede verse que una amplia mayoría de la población (62\%) no cree que el Estado esté llevando adelante acciones para reducir la desigualdad en salud, mientras que un $30 \%$ considera que sí lo hace. De esta proporción, casi el $80 \%$ percibe que estas acciones no son suficientes. 


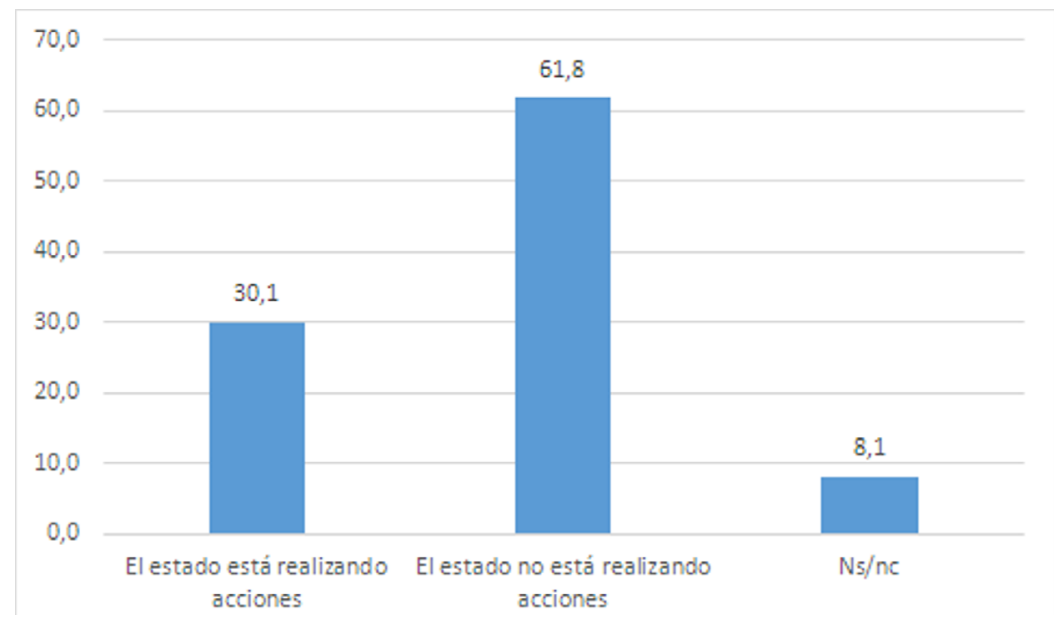

Figura 4. Percepción de la población respecto a las acciones del Estado para reducir la desigualdad en salud. Provincia de Córdoba. En porcentajes. $n=800$

Fuente: elaboración propia con base en encuesta Presides 2016

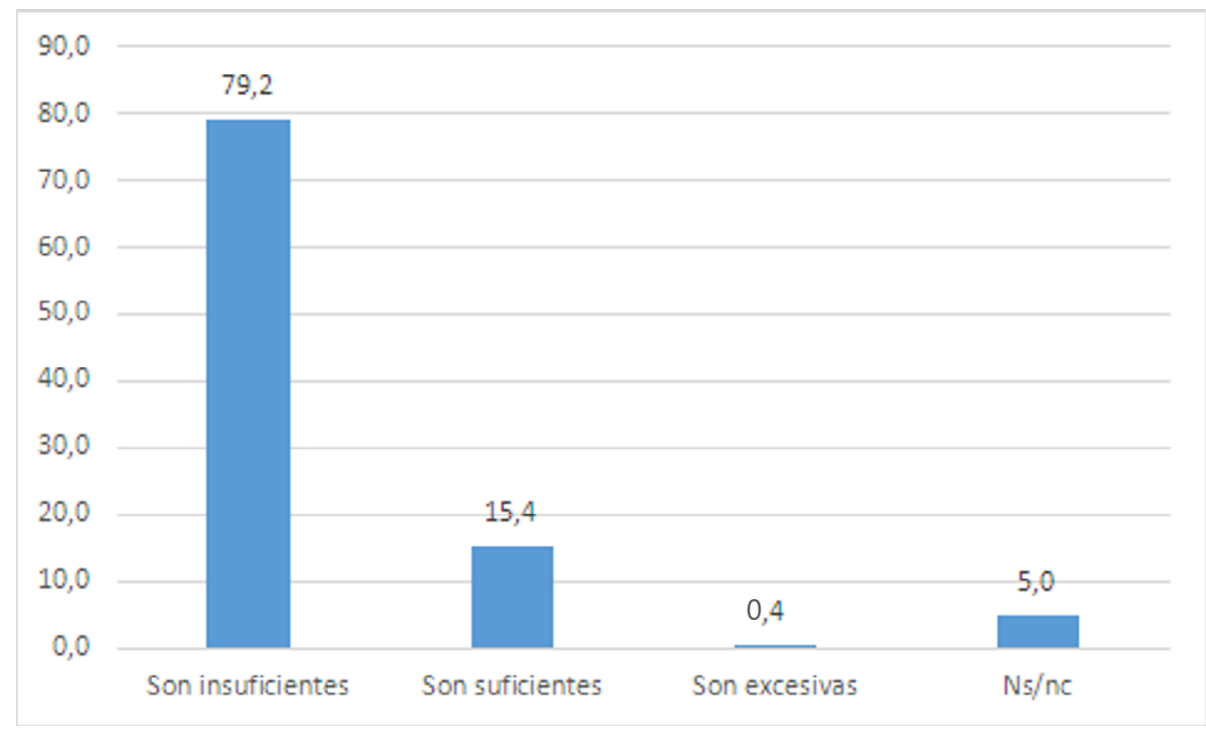

Figura 5. Percepción de la población respecto a si las acciones del Estado para reducir la desigualdad en salud son suficientes. Provincia de Córdoba. En porcentajes. $n=246$

Fuente: elaboración propia con base en encuesta Presides 2016

El cruce entre estas tres variables (si el Estado debe realizar acciones para reducir la desigualdad, si está realizando acciones en este sentido y si tales acciones son suficientes) permite establecer una distribución de la pobla- 
ción según lo que se puede considerar una proxy de la intensidad de sus preferencias redistributivas en la dimensión salud.

Las preferencias redistributivas más intensas corresponderán a quienes están muy de acuerdo con que el Estado debe realizar acciones, pero consideran que no las realiza o las realiza y son insuficientes. En segundo lugar se ubican quienes están de acuerdo con que el Estado debe realizar acciones y consideran que no las realiza o son insuficientes. Luego se ubican dos categorías de menor intensidad: quienes están muy de acuerdo y quienes están de acuerdo con que el Estado debe llevar adelante acciones y consideran que este sí realiza acciones en este sentido. Posteriormente, quienes creen que el Estado no debe llevar adelante acciones redistributivas y finalmente una categoría residual de quienes no saben si este debe llevar adelante este tipo de acciones. La distribución de la población en estas categorías se muestra en la figura 6 .

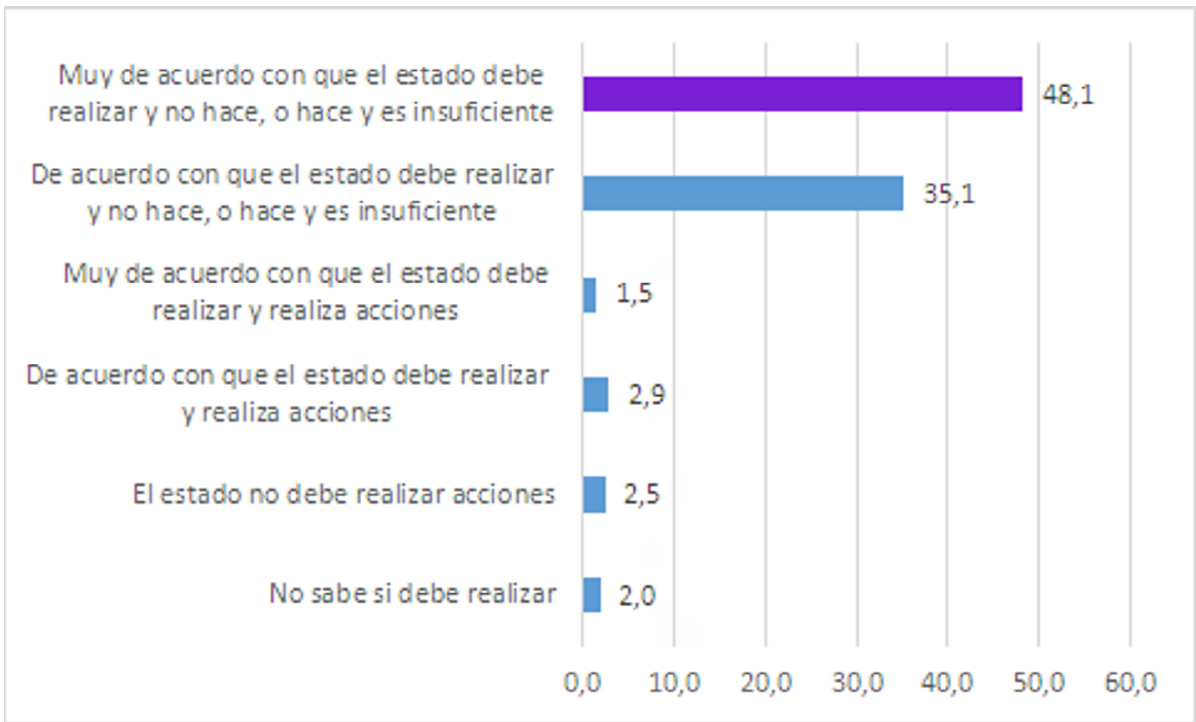

Figura 6. Percepción respecto a lo que el Estado debe hacer y hace en relación con la desigualdad en salud. Provincia de Córdoba. En porcentajes. $n=800$

Fuente: elaboración propia con base en encuesta Presides 2016

Las dos primeras categorías que corresponden a las preferencias redistributivas más intensas comprenden más del $83 \%$ de la población. 
Sin embargo, a nuestro juicio, entre estas dos categorías hay una diferencia importante en términos de lo que implican respecto a un apoyo político explícito y activo a políticas redistributivas. Podemos asumir razonablemente que quienes están muy de acuerdo con que el Estado implemente esquemas redistributivos y creen que no hace nada al respecto, o lo que hace no es suficiente, estarán predispuestos a involucrarse más activamente en la promoción, o al menos a ser más políticamente sensibles (a través del voto) respecto a políticas de este tipo que quienes, aun cuando creen también que el Estado no hace o lo que hace no es suficiente, están solo de acuerdo con que este debe llevar adelante acciones redistributivas. Simplificando, podemos decir que los primeros ofrecerán apoyo político a los esquemas redistributivos mientras que los segundos no se opondrán a políticas de este tipo. Llamaremos a las preferencias de quienes están en la primera categoría preferencias redistributivas políticamente activas (abreviadamente las llamaremos preferencias activas).

¿Qué factores inciden para que se den preferencias de este tipo a nivel individual?

Con el fin de explorar respuestas a esta pregunta y tal como mencionáramos en el apartado metodológico, aplicamos modelos logit binominal, donde la variable dependiente es presencia de preferencias activas.

Las variables ingreso y autopercepción del estado de salud nos permiten testear las expectativas teóricas de dos de las teorías de actores racionales autointeresados: la de actores focalizados en el presente y la de actores que toman en cuenta el futuro ${ }^{2}$.

De acuerdo con la primera teoría, esperaremos que ambas variables se relacionen significativa y negativamente con la preferencia activa. De acuerdo con la segunda teoría, la expectativa teórica es que solo el ingreso se relacione negativamente con la variable dependiente.

La variable ingreso nos permite también verificar en qué medida se verifican las previsiones del grupo de teorías que postulan la vigencia de un altruismo racional en sus variantes del "beneficio del donante" y de los merit goods. Como vimos, de acuerdo con estas teorías, cabe esperar que la variable ingreso sea significativa pero, contrariamente a lo previsto por las teorías de la racionalidad autointeresada, relacionada positivamente 
con la variable dependiente (véase tabla 2; modelos 3, 8 y 9). En cuanto al enfoque "sociotrópico" de este grupo de teorías, para establecer en qué medida la lógica de consideración del contexto incide sobre las preferencias activas, introdujimos una variable que registra si el encuestado considera que la desigualdad genera un problema para su grupo familiar (valor de la variable $=1$ ) o no lo genera (valor de la variable $=0$ ). Lo previsto por esta mirada teórica es que esta variable se relacione positivamente con la variable dependiente.

Finalmente, respecto al grupo de teorías biológico-evolucionistas y socioantropológicas que señalan la existencia de una solidaridad basada en la intensidad de interacciones con grupo vulnerables o de riesgo en materia de salud, la encuesta no nos provee de indicadores directamente vinculados con este concepto. Sin embargo, creemos que la variable sexo en contextos predominantemente patriarcales como los de América Latina, en los cuales las mujeres desempeñan en mucho mayor medida que los hombres tareas de cuidado en el grupo familiar, puede considerarse una proxy de aquella variable teórica. La expectativa teórica es que las mujeres tengan más posibilidades de tener preferencias activas que los hombres. Bajo la inspiración de este grupo de teorías, definimos también la variable miembro de organizaciones voluntarias. La asunción es que quienes se involucran en este tipo de organizaciones están movidos por sentimientos de mayor solidaridad que quienes no forman parte de ellas, con lo que cabe esperar que aquellas personas tengan más chance de tener preferencias activas que estas.

Como variables de control, en cuanto esperamos que tengan incidencia tanto sobre la variable dependiente como sobre una o más de las dependientes, introdujimos ideología (autoposicionamiento ideológico en una escala de derecha a izquierda) y educación (por nivel educativo, con el menor nivel como categoría de referencia). Los resultados del análisis se muestran en la tabla 2 .

En el modelo 8 se introdujo la totalidad de las variables y en el modelo 9 se retiró la variable educación que en el modelo 8 aparece como no significativa.

La variable ingreso es significativa en todas las categorías, siendo la categoría de referencia (los ingresos más altos) la que tiene mayores posibilidades de coincidir con el valor positivo de la variable dependiente (véase tabla 2 . Modelos 3, 8 y 9). 
Tabla 2. Modelos de regresión logística. Coeficientes exp(b). Variable dependiente: preferencia redistributiva políticamente activa (muy de acuerdo con que el estado debe realizar acciones y no realiza, o realiza y son insuficientes)

\begin{tabular}{|c|c|c|c|c|c|c|c|c|c|c|}
\hline & & M1 & M2 & M3 & M4 & M5 & M6 & M7 & M8 & M9 \\
\hline & Constante & $0,78^{*}$ & 0,87 & $1,84^{\star \star \star}$ & $0,82^{*}$ & $0,39^{\star \star}$ & $0,8^{\star \star}$ & $0,69^{\star \star \star}$ & 0,67 & 0,73 \\
\hline \multirow{3}{*}{$\begin{array}{l}\frac{\pi}{\bar{O}} \\
\text { 응 } \\
\frac{d}{0}\end{array}$} & Izquierda & $2,04^{\star * *}$ & & & & & & & $1,88^{\star *}$ & $1,79^{* *}$ \\
\hline & Centro & $1,4^{*}$ & & & & & & & 1,31 & 1,33 \\
\hline & (Derecha) & 1 & & & & & & & 1 & 1 \\
\hline \multirow{3}{*}{ 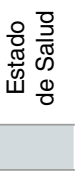 } & Muy bueno y bueno & & 1,085 & & & & & & & \\
\hline & $\begin{array}{l}\text { (Regular, malo } \\
\text { y muy malo) }\end{array}$ & & 1 & & & & & & & \\
\hline & & M1 & M2 & M3 & M4 & M5 & M6 & M7 & M8 & M9 \\
\hline \multirow{5}{*}{ 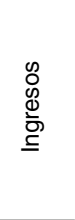 } & Menos de $\$ 5000$ & & & $0,37^{\star \star \star}$ & & & & & $0,38^{\star \star}$ & $0,35^{\star \star \star}$ \\
\hline & $\$ 5000$ a $\$ 10.000$ & & & $0,37^{\star * *}$ & & & & & $0,35^{\star * *}$ & $0,34^{* * *}$ \\
\hline & $\$ 10.001$ a $\$ 20.000$ & & & $0,48^{\star \star}$ & & & & & $0,48^{\star \star}$ & $0,47^{\star \star \star}$ \\
\hline & $\$ 20.001$ a $\$ 30.000$ & & & $0,53^{\star *}$ & & & & & $0,45^{\star \star}$ & $0,45^{\star \star}$ \\
\hline & (\$30.001 y más) & & & 1 & & & & & 1 & 1 \\
\hline \multirow{2}{*}{ 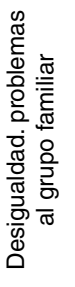 } & Si genera problemas & & & & 1,18 & & & & $1,56^{\star \star}$ & $1,61^{\star \star \star}$ \\
\hline & $\begin{array}{l}\text { (No genera } \\
\text { problemas) }\end{array}$ & & & & 1 & & & & 1 & 1 \\
\hline \multirow{6}{*}{ 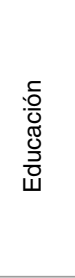 } & (Primario incompleto) & & & & 1 & & & 0,96 & & \\
\hline & Primario completo & & & & 1,6 & & & 0,978 & & \\
\hline & Sec.incompleto & & & & 1,36 & & & 0,726 & & \\
\hline & Sec. completo & & & & 1,94 & & & 1,211 & & \\
\hline & Superior incompleto & & & & $3,1^{\star \star}$ & & & 1,148 & & \\
\hline & Superior completo & & & & $3,07^{\star \star}$ & & & 1 & & \\
\hline \multirow{2}{*}{$\begin{array}{l}\text { × } \\
\text { ஸे }\end{array}$} & Mujer & & & & & & $1,31^{*}$ & & $1,54^{\star \star}$ & $1,51^{\star \star}$ \\
\hline & (Varón) & & & & & & 1 & & 1 & 1 \\
\hline \multirow{2}{*}{ 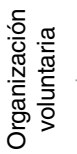 } & Miembro & & & & & & & $1,83^{\star \star *}$ & $1,83^{\star \star \star}$ & $1,84^{\star \star \star}$ \\
\hline & (No miembro) & & & & & & & 1 & 1 & \\
\hline
\end{tabular}

${ }^{*} p<0,1 ;{ }^{* *} p<0,05 ;{ }^{* *} p<0,01$

Nota: entre paréntesis y cursiva, la categoría de referencia.

Fuente: elaboración propia con base en la encuesta Presides 2016 
Estas posibilidades decrecen significativa y consistentemente a medida que baja la escala de ingresos. Por su parte, la variable autopercepción del estado de salud no es significativa (ni en el modelo 2 en el que se la usa como única variable explicativa, ni cuando se la incluye en el modelo multivariable). El comportamiento de ambas variables contraría las previsiones de las teorías del autointerés racional focalizado en el presente. En el caso de la teoría que asume actores que contemplan el futuro, si bien el comportamiento de la variable autopercepción del estado de salud se da de acuerdo con sus previsiones (no tiene efecto sobre las preferencias redistributivas), el de la variable ingreso se opone a sus expectativas.

No obstante, este comportamiento de la variable ingresos (a mayores ingresos, mayores posibilidades de tener preferencias activas) sí coincide con las previsiones del grupo de teorías del altruismo racional, aunque como señaláramos en el apartado anterior, no es posible establecer si los mecanismos explicativos que subyacen a esta relación corresponden a las teorías del beneficio del donante o a las de merit goods. Cabe destacar la intensidad de la relación: quienes se ubican en el tramo de ingreso más alto (categoría de referencia) tienen casi tres veces más posibilidades de tener preferencias activas que quienes están en el tramo más bajo.

La variable desigualdad genera problemas al grupo familiar no es significativa en su correspondiente modelo bivariado (véase tabla 2, modelo 4), pero adquiere significación en el modelo multivariado (modelos 8 y 9) en un sentido que es consistente con la teoría de la racionalidad sociotrópica: aquellos que creen que la desigualdad traerá problemas a su grupo familiar tienen más posibilidades de apoyar activamente políticas redistributivas que quienes no creen de este modo.

Finalmente, tanto las variables sexo (tabla 2, modelos 6, 8 y 9) como miembro organización voluntaria (tabla 2, modelos 7, 8 y 9) son significativas, tanto en sus correspondientes modelos bivariados como en el modelo multivariado. El sentido de su relación (las mujeres tienen aproximadamente 50\% más posibilidades de tener preferencias activas que los varones, y quienes pertenecen a una organización voluntaria tiene por arriba del $80 \%$ más posibilidades de tener este tipo de preferencias que quienes no pertenecen a este tipo de organizaciones) satisfacen las expectativas teóricas de las perspectivas que sostienen la explicación de preferencias redistributivas por la existencia de sentimientos de solidaridad generados ya sea por 
expectativas de reciprocidad, o por interacciones cotidianas con quienes están en posiciones más vulnerables (si bien la variable sexo presta en realidad más sustento empírico a este último mecanismo que al primero).

En cuanto a las variables de control, la variable educación, si bien es significativa en las categorías superiores en el modelo bivariado correspondiente (tabla 2, modelo 5), carece de significación en el modelo multivariado (modelos 8 y 9), lo cual puede atribuirse a su correlación con la variable ingreso. Por su parte, la variable ideología es significativa y su relación con la variable dependiente tiene el sentido esperado: quienes se autocalifican de izquierda tienen más del doble de posibilidades de apoyar activamente políticas redistributivas que quienes se consideran de derecha (tabla 2, modelos 1,8 y 9).

En la figura 7, con el fin de hacer más ilustrativas las diferencias entre distintos segmentos poblacionales respecto a las preferencias activas, se muestran las proporciones de la población con este tipo de preferencias para cada categoría de las variables estadísticamente significativas (con el fin de una mejor percepción de las diferencias se incluye $-\mathrm{y}$ se prolonga con línea punteada- la proporción total de la población con preferencias redistributivas activas). 


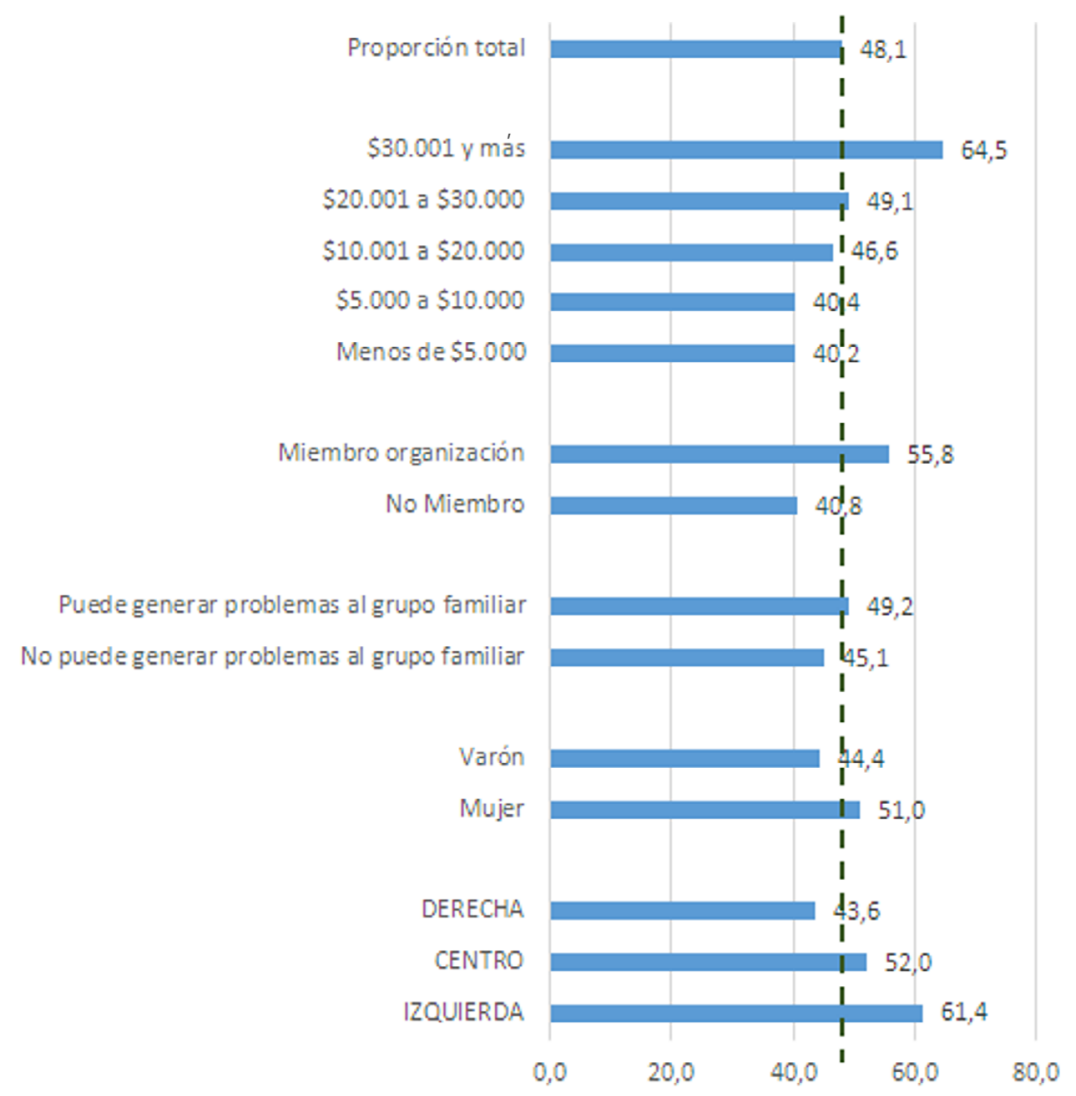

Figura 7. Proporción de población con preferencias redistributivas altas activas (que está muy de acuerdo con que el estado debe realizar acciones y no realiza, o realiza y son insuficientes) según diferentes factores: ingresos, miembro de organización, nivel educativo, sexo e ideología. Provincia de Córdoba. $n=800$

Fuente: elaboración propia con base en encuesta Presides 2016

Puede percibirse claramente que la mayor diferencia entre las categorías extremas se da en la variable ingreso (64\% contra 40,2\%).

A partir de estos resultados pueden establecerse con cierta precisión las características socioeconómicas del grupo poblacional que con mayor intensidad relativa apoyará esquemas redistributivos en materia de atención sanitaria: mujeres de altos ingresos que pertenecen a organizaciones de la sociedad civil. 


\section{Discusión}

Un elemento muy importante respecto a la probabilidad y la viabilidad política de acciones estatales que apunten a reducir las desigualdades es la opinión pública. El registro de tales desigualdades por una proporción relevante de la población y, con base en este registro, y la existencia de actitudes favorables a la implementación de esquemas redistributivos, hacen mucho más probable la adopción de políticas redistributivas y contribuyen a su implementación y sostenimiento a lo largo del tiempo. No obstante, son prácticamente nulos los estudios en América Latina sobre la opinión pública y las preferencias redistributivas en la dimensión salud.

El caso de Córdoba analizado ofrece una primera aproximación en este campo, con algunos resultados sustantivos que, si bien no son automáticamente generalizables al resto de la Argentina y la región, constituyen un aporte relevante para la caracterización de las percepciones de desigualdad y las preferencias redistributivas en atención sanitaria en el contexto latinoamericano.

Uno de nuestros hallazgos relevantes es que más de la mitad de la población percibe las desigualdades en atención médica como altas o muy altas, lo que indica que las desigualdades que se expresan en indicadores objetivos, como por ejemplo las brechas en mortalidad infantil, tienen un reflejo subjetivo en la mayoría de la población.

Un segundo hallazgo es que una abrumadora mayoría de la población tiene preferencias redistributivas, en cuanto está muy de acuerdo o de acuerdo con que el Estado debe realizar acciones para reducir las desigualdades en el acceso a la atención médica adecuada, pero también considera que o no está llevando adelante acciones de este tipo o las que lleva adelante no son suficientes. Esto implica que potenciales políticas orientadas a reducir la desigualdad tendrán un amplio apoyo social.

No obstante, dado que el tener preferencias redistributivas no necesariamente implica que se apoyará activamente políticas de este tipo, hicimos una distinción en estas preferencias según su intensidad. Introdujimos, así, la noción de preferencias redistributivas activas que corresponde a quienes están muy de acuerdo con que el estado debe llevar adelante políticas redistributivas y creen que el Estado no hace nada al respecto o que lo que hace 
no es suficiente. Asumimos que estas personas están más dispuestas a apoyar activamente, que quienes solo están de acuerdo, esquemas redistributivos en la dimensión salud o, al menos, a estar más atentos respecto a su existencia o no y a actuar (así más no sea electoralmente) de acuerdo con estos registros. Casi la mitad de la población tiene este tipo de preferencia redistributiva activa. Consideramos a este nuestro tercer hallazgo de importancia.

Un cuarto hallazgo de relevancia refiere a los factores determinantes de este tipo de preferencia redistributiva. De acuerdo con los resultados de nuestros modelos econométricos, los factores que inciden significativamente sobre la existencia o no de preferencias redistributivas son el ingreso (los individuos de mayores ingresos tienen más posibilidades de tener estas preferencias que los de menores ingresos), el sexo (las mujeres tienen más posibilidades que los hombres), el considerar que la desigualdad puede generar problemas al grupo familiar (quienes así lo consideran tienen más posibilidades que quienes no lo creen así) y la pertenencia a una organización voluntaria (quienes integran una organización tienen más posibilidades que quienes no).

Según entendemos, este hallazgo tiene un triple valor. En primer lugar, nos permite caracterizar al grupo poblacional en el que habrá mayor prevalencia de preferencias activas: mujeres de relativamente altos ingresos (al menos por encima de la media) y que pertenecen a organizaciones voluntarias. Desde el punto de vista de la viabilidad política, este es el grupo poblacional al que los gobiernos y funcionarios interesados en llevar adelante políticas redistributivas deberían tratar de involucrar activamente en diferentes formas de apoyo político.

En segundo lugar, al mostrarnos cuáles son los mecanismos teóricos que dan cuenta, mejor que otros, de la presencia o no de preferencias activas, permite establecer el tipo de apelación al que se debe recurrir para reforzar o poner en marcha el apoyo social a los esquemas redistributivos por parte de aquellos grupos predispuestos a otorgarlo activamente. En efecto, las teorías de racionalidad autointeresada no son relevantes para explicar las preferencias activas, mientras que sí lo son las que incorporan nociones de altruismo y solidaridad, ya sean sus raíces racionales (basada en expectativas de reciprocidad o en la valoración de los beneficios individuales que resultan de una sociedad libre de problemas acuciantes) o emocionales (identificación con los problemas de aquellos en situación más desventajosa). La retórica política de las políticas redistributivas, por lo tanto, debería hacer hincapié 
en estos valores de solidaridad, resaltando tanto los aspectos "racionales" como los "emotivos" de esta, al tiempo que debería relegar las referencias a sus beneficios puramente individuales.

En tercer lugar, el modo en que el ingreso incide sobre la existencia de preferencias activas (a medida que aumenta el ingreso son mayores las posibilidades de que estas preferencias existan) es relevante respecto a cuál tipo de política redistributiva tendrá más probabilidades de tener apoyo político de los ciudadanos. En efecto, como señala McGuire (23) hay dos grandes perspectivas respecto a los factores que inciden tanto sobre los niveles de salud de la población como sobre las desigualdades en esta dimensión. Por un lado, la hipótesis whealthier is healthier sostiene que los niveles de salud individuales y, por ende, los agregados (medidos, por ejemplo, a través de la tasa de mortalidad infantil) dependen básicamente del ingreso y de la desigualdad en la distribución de este. Por lo tanto, la estrategia adecuada para mejorar la salud de una población dada es aumentar el ingreso medio y reducir la desigualdad de ingresos. Por el otro lado, la hipótesis de social servicies provision sostiene, sin negar la importancia que tiene el ingreso, que los factores más relevantes para mejorar la salud de la población en países en desarrollo y con elevada pobreza, es asegurar la provisión más amplia posible de servicios básicos, incluyendo atención primaria, planeamiento familiar, agua potable y educación sanitaria. Mientras el aumento del ingreso medio y su más igualitaria distribución es, en el mejor de los casos un proceso lento, sostiene esta mirada, a través de la provisión de servicios básicos (lo que normalmente implica un esfuerzo presupuestario no extremadamente grande en términos relativos) puede darse un avance rápido en la mejora de la salud de la población y en la reducción de las desigualdades sanitarias.

Más allá de sus respectivos méritos intrínsecos, la cuestión de cuál de estas visiones tiene más posibilidades de conseguir apoyo político de la población remite a las características, en cuanto a ingresos, de los grupos poblacionales más propensos a sostener esquemas redistributivos, ya que son estos grupos los que apoyarán más uno u otro tipo de política, mientras que quienes no tienen preferencias redistributivas son indiferentes a ambos tipos alternativos.

Como vimos, en el caso de Córdoba, los grupos con preferencias redistributivas son los de más altos ingresos. Esto implica que las políticas de servicios 
básicos tienen mayor viabilidad que políticas inspiradas en la hipótesis wealthier is healthier. En efecto, como las preferencias redistributivas de estos grupos son relativas a la dimensión salud, es probable que, mientras se opongan a políticas de redistribución de ingresos (que al tiempo que los perjudica directamente tiene una conexión indirecta y no obvia con la equidad en salud), apoyen políticas de servicios básicos, directamente y muy visiblemente relacionadas con el mejoramiento en la salud de los sectores más desfavorecidos. Por su parte, los sectores de menores ingresos no se opondrán a políticas de este tipo (aunque pudieran preferir políticas de redistribución de los ingresos por sobre políticas de servicios básicos). De este modo, políticas inspiradas en la hipótesis wealthier is healthier tendrán el apoyo de los sectores de menores recursos y la oposición de aquellos de más altos ingresos, mientras que las políticas de servicios básicos tendrán el apoyo de sectores de ingresos más altos y no enfrentarán la oposición (incluso quizá tengan también cierto apoyo) de los sectores de ingresos menores.

Como síntesis final, podemos decir, entonces, que la viabilidad política de esquemas redistributivos en la provincia de Córdoba será mayor si: (i) los funcionarios apuntan a movilizar en apoyo de estas políticas a sectores de altos ingresos (y, dentro de ellos, sobre todo mujeres que participen en asociaciones voluntarias); (ii) la apelación a estos grupos se hace con una retórica que enfatice los aspectos solidarios implicados en tales esquemas y (iii) estos esquemas consisten, principalmente, en la provisión de servicios básicos a los sectores menos favorecidos.

\section{Referencias}

1. Organización Mundial de la Salud. Lograr la equidad en salud: desde las causas iniciales a los resultados justos. Comisión sobre Determinantes Sociales de la Salud. Declaración provisional; 2008. Disponible en: http://apps.who.int/iris/ bitstream/handle/10665/69671/interim_statement_spa.pdf?sequence =1\&isAllowed $=\mathrm{y}$

2. Organización Mundial de la Salud. Cerrando la brecha: la política de acción sobre los determinantes sociales se la salud. Documento de trabajo. Organización Mundial de la Salud. Río de Janeiro, Brasil. 2011.

3. Organización Mundial de la Salud. Subsanar las desigualdades en una generación: alcanzar la equidad sanitaria actuando sobre los determinantes sociales de la salud. Argentina. 2009. 
4. Organización Panamericana de la Salud. Monitoreo de las desigualdades en salud, Con especial énfasis en países de ingresos medianos y bajos. Washington: OPS; 2016.

5. Sapag JC, Kawachi I. Capital social y promoción de la salud en América Latina. Saúde Pública. 2007;41(1):139-49.

6. Almeida C. Reformas del sector salud y equidad en América Latina y el Caribe: Conceptos, agenda, modelos y algunos resultados de implementación. Gerencia y Políticas de Salud. 2005;4(9):6-60.

7. Cepal. Población y salud en América Latina y el Caribe: retos pendientes y nuevos desafíos. Santiago de Chile: Cepal; 2010.

8. Abramovich V, Pautassi L. El derecho a la salud en los tribunales. Algunos efectos del activismo judicial sobre el sistema de salud en Argentina. Salud Colectiva. 2008;4(3):261-82. Disponible en: http://www.scielo.org.ar/pdf/sc/v4n3/v4n3a02.pdf

9. Cepal. Implementación del Programa de Acción de la Conferencia Internacional sobre la Población y el Desarrollo en América Latina y el Caribe. Examen del periodo 2009-2013 y lecciones aprendidas. Síntesis y balance. Santiago de Chile: Cepal; 2013.

10. DEIS. Estadísticas vitales. Información básica. Argentina año 2015. Dirección de Estadísticas e información en salud, Ministerio de Salud, Presidencia de la Nación. Serie 5, número 59. Buenos Aires. 2016. Disponible en: http://www.deis. msal.gov.ar/wp-content/uploads/2016/12/Serie5Numero59.pdf.

11. Harrington I, Rojas Cabrera E, Santillán Pizarro M. Familias en foco: mortalidad infantil en Argentina y Brasil a la luz de los derechos humanos. En: Celton D, Irigoyen López A, editores. Miradas históricas sobre familias argentinas. Murcia: Editorial Universidad de Murcia; 2011. p. 237-62.

12. Rojas Cabrera E, Santillán Pizarro MM. La mortalidad infantil en la provincia de Córdoba desde un enfoque de derechos. En: Observatorio de Derechos Humanos de la Secretaría de Extensión Universitaria de la Universidad Nacional de Córdoba. Informe de derechos económicos, sociales y culturales en Córdoba. Córdoba: Universidad Nacional de Córdoba; 2015. p. 15-28.

13. Arraigada I, Aranda V, Miranda F. Políticas y programas de salud en América Latina. Problemas y propuestas. Santiago: Cepal, Serie Políticas Sociales, 114; 2005.

14. Wagstaff A. Pobreza y desigualdades en el sector de la salud. Revista Panamericana de Salud Pública. 2002;11(5/6):316-26.

15. Almeida N, Kawachi I, Pellegrini A, Dachs N. Reserarch on health inequalities in Latina America and the Caribbean: bibliometric analysis (1971-2000) and descriptive contente analysis (1971-1995). American Journal of Public Health. 2003;93(12):2037-43. 
16. Alesina A, La Ferrara E. Preferences for redistribution in the land of opportunities. Cambridge: NBER Working Paper Series, working paper 8267; 2001.

17. Kenworthy L, Mc Call L. Inequality, public opinion, and redistribution. Londres: LIS Working Paper Series, No. 459; 2007.

18. Cruces G, Tetaz M. Percepciones subjetivas de la distribución del ingreso y preferencias por las políticas redistributivas. Avances de Investigación 33. Buenos Aires: Fundación Carolina. 2009.

19. Gaviria A. Social mobility and preferences for redistribution in Latin America. Manuscrito. CEDE - Universidad de San Andrés. 2006.

20. James C, Savedoff W. Risk pooling and redistribution in health care: an empirical analysis of attitudes toward solidarity. Ginebra: World Health Organization world health report, background paper 5; 2010.

21. Haveman R, Weisbrod. B. Definición de los beneficios de los programas públicos: algunas directrices para analistas de políticas. En: Haveman R, Margolis J, editores. Un análisis del gasto y las políticas gubernamentales. México: Fondo de Cultura Económica; 1992. p. 106-32.

22. Margolis H. Selfishness, altruism and rationality. Cambridge: Cambridge University Press; 1982.

23. McGuire J. Wealth, health, and democracy in East Asia and Latina America. Nueva York: Cambridge University Press; 2010.

24. Notas

Anexo.

Construcción de las variables de los modelos de regresión

\section{Variable dependiente. Presencia de preferencias redistributivas políticamente activas}

Se operacionalizó a partir de la combinación de las respuestas a tres pre-guntas del cuestionario:

1. Según su opinión, por favor diga si está de acuerdo con la siguiente afirmación: "El Estado debe realizar acciones para reducir la desigualdad en salud".

1. Muy de acuerdo

2. De acuerdo

3. Sin opinión formada

4. Desacuerdo

5. Muy en desacuerdo 
2. Según su opinión, ¿considera que el Estado está realizando acciones para reducir las desigualdades en salud?

1. Está realizando

2. No está realizando (pase a la siguiente columna)

3. ¿Ud. considera que esas acciones son suficientes?

1. Son insuficientes

2. Son suficientes

3. Son excesivas

Se considera que la persona tiene preferencias redistributivas si está muy de acuerdo con que el Estado debe realizar acciones para reducir las desigualdades en salud y si cree que el Estado no está realizando acciones o si el Estado realiza acciones que son insuficientes. La proporción de población con esta percepción asciende a un 48,1\% $(=33,9 \%+14,3 \%)$ (tablas 1 y 2$)$.

\section{Variables independientes}

Ideología política

En el cuestionario, la pregunta se formuló de la siguiente manera: En temas políticos, la gente habla de "la izquierda" y "la derecha". De acuerdo con sus opiniones, y de acuerdo con una escala en la que 1 significa izquierda y 7 significa derecha, ¿dónde se colocaría $U d$. en esta escala?

Las categorías de la variable quedaron construidas de la siguiente manera: izquierda (categorías 1 a 3); centro (categoría 4); derecha (categorías 5 a 7).

\section{Autopercepción del estado de salud}

En el cuestionario, la pregunta se formuló de la siguiente manera:

En general, ¿cómo describiría su estado de salud últimamente? Diría que es ¿muy buena, buena, regular, mala o muy mala?

\section{Ingresos}

Refiere a los ingresos totales del hogar. La pregunta se formuló de la siguiente manera: 
¿En cuál de los siguientes rangos se encuentran los ingresos familiares mensuales de este hogar, incluyendo los ingresos de todos los adultos que trabajan? Las opciones son: menos de \$5000; $\$ 5000$ a $\$ 10.000 ; \$ 10.001$ a \$20.000; \$20.001 a \$30.000; 30.001 y más.

\section{Desigualdad genera problemas al grupo familiar}

La pregunta en el cuestionario se formuló del siguiente modo: $\dot{c} U d$. cree que las desigualdades en salud pueden generar algún problema que afecte a su grupo familiar? (Opciones de respuesta Sí/No).

\section{Educación}

El nivel educativo se operacionaliza a partir de dos preguntas: la primera es ¿Qué nivel educativo cursa o cursó? Las respuestas son: primario, secundario, terciario, universitario, post-universitario. La segunda es: ¿Completó ese nivel? Con respuestas Sí/No.

\section{Sexo}

La variable sexo se registra a partir de la observación del encuestador. Las opciones son varón y mujer.

\section{Miembro organización voluntaria}

La pregunta en el cuestionario se formuló del siguiente modo: Ahora voy a leerle una lista de organizaciones voluntarias. ¿Podría decirme, para cada una de ellas, si Ud. es miembro y si participa activamente? Las opciones de respuestas eran: organizaciones religiosas; organizaciones deportivas o recreativas; organizaciones artísticas, musicales o educativas; centros de estudiantes; sindicatos; partidos políticos; organizaciones medioambientales; asociaciones profesionales; organizaciones humanitarias o de caridad; grupos de autoayuda o de ayuda mutua; centros vecinales; organizaciones empresariales; otras organizaciones, ¿cuáles?

A partir de las respuestas se creó una variable dicotómica Miembro de organización voluntaria con opciones Sí/No. Se considera "Sí" si la persona es miembro de al menos una organización. "No" en el caso de que no sea miembro de ninguna organización. 


\section{Notas}

1 Como señaláramos más arriba, hay una implicación conceptual entre reducción de la desigualdad y políticas redistributivas, ya que no puede darse la primera sin que se apliquen medidas de redistribución por parte del Estado (si bien es cierto que puede darse una reducción de la desigualdad sin intervención estatal; es claro, sin embargo, que estos mecanismos no estatales de reducción de la desigualdad no han funcionado, al menos de modo relevante, hasta ahora en América Latina). De allí que se puede suponer que quien prefiere que el Estado actúe para reducir la desigualdad está "revelando" preferencias redistributivas. Metodológicamente, creemos que abordar la cuestión con preguntes referidas a la acción del Estado que inciden sobre la desigualdad antes que referidas a políticas redistributivas es adecuado, en cuanto se pude suponer que para el encuestado la pregunta adquiere contornos mucho más concretos en el primer caso que en el segundo. Queda abierta la posibilidad de que las implicancias redistributivas de acciones del Estado que se orientan a reducir la desigualdad no estén claras en la mente de los encuestados. Aun así, creemos que es posible hacer una interpretación teórica basada en esta implicancia, dado que, en última instancia, "preferencias por acciones del Estado que reduzcan la desigualdad" y "preferencias redistributivas" son complementarias y no opuestas (es difícil pensar que quien tenga la primera cambiará su opinión al percatarse de que también implica la segunda).

2 Como señalamos en el apartado anterior, la tercera de las teorías de este grupo, la basada en el concepto de "aversión al riesgo", requiere para su testeo de la construcción de indicadores específicas para medir los niveles de esta aversión. Dado que en la encuesta del Presides no se contemplaron indicadores de este tipo, no introducimos en nuestro modelo variables relacionadas con esta teoría. 